\title{
The Study of Changes in Tomato Herbaceous Species Using Municipal Composts of Mashhad City
}

\author{
Ali Najafi ${ }^{1}$, Abolfazl Karimiyan ${ }^{1}$, Bahman Reza Khorshidi ${ }^{1}$, \\ Hossein Meiboudi $*^{2}$ \\ ${ }^{1}$ Waste Management organization of Mashhad Municipality, Iran \\ ${ }^{2}$ Ph.D Student of Environmental Management, IAU, Science and Research Branch, Tehran, Iran
}

\begin{abstract}
While environmental and economic adversities in waste disposal and the decrease of organic soil have caused the enhancement of municipal composts' production and application, it is of great importance to choose and utilize an appropriate fertilizer in order to amend the soil. Therefore, the effects of using three types of municipal composts (powdered compost, sulphur granular compost, and sulphur granular compost with thiobacillus inoculum amounting $2 \%$ of sulphur) and their amounts were assessed through the application of complete randomized block design with a $3 \times 5$ factorial experiment in five rates of zero (control), 15, 30, 45, and 60 tons per hectare to plant tomato. These experiments were started in 2008 and repeated three times during the following years. The achieved findings indicated that applying municipal composts is useful in planting tomato. The comparison of various types of composts proved that scholars should place more priority on sulphur granular compost, rather than two other kinds.
\end{abstract}

Keywords: Municipal Composts, Waste Disposal, Mashhad City, Tomato

\section{INTRODUCTION}

In developing countries, a decline in organic matter of arable soils and the process of decays in soil performance, and also residues which are returned to the soil are all caused by disregarding new technical advantages and knowledge, soil and water limitations, high density plantation, small surfaces of planted soil and increased rate of subsistence farming. A good supply of soil organic matter can prevent from soil decays. Organic matter is the key factor of chemical, physical and biological soil properties which indicates soil fertility and productivity. Iran, especial Khorasan province, is located in an arid and semi-arid region consisting of the soil with low organic contents due to the dry climates. Keshavarz stated that the amount of organic carbon is less than critical level in all regions of Khorasan Razavi province. However, high level of PH in the soil and presence of bicarbonate ion in the water have redoubled problems of plant nutrition. The obtained results of various researches indicated that sulphur can deplete PH in calcareous soil, and increase the solubility of micronutrients such as phosphorus, and also amend halomorphic and sodic soils in inappropriate waters. Some soil properties such as moisture and organic matter can enable thiobacillus bacteria to oxidize the sulphur and make it sulphuric acid, but in Iran, owing to the low rate of organic matter in arable soils, the aforementioned process does not appropriately occur.

On the other hand, different environmental and economic problems in waste disposal can cause the enhancement of municipal composts' production and application; therefore, lots of composts have been produced in different European, American and other countries by applying advanced facilities and machineries with high efficiency and capacity to control the process of soil productivity. Utilizing compost is beneficial in many ways, for instance it can amend the soil organic matter to provide useful bacteria such as sulphuroxidizing bacteria. Improving the status of soil productivity is subject to increasing the rate of sulphur and municipal composts as sources of organic soil, and applying calcareous soil with a suitable level of $\mathrm{PH}$, and also enhancing the amount of nutrients' solubility such as phosphorus, iron, manganese, and zinc. So, the current study aims to investigate the effectiveness of various municipal composts in tomato.

\section{Review of literature}

In many conducted researches, sulphur is considered as an acid-generating material which is capable of amending calcareous and sodic soils [2]. Sulphur is of great importance due to its beneficial effects when acidifying the local soil and increasing the capability of solubility in nutrients. Kalbasi et al. [21] conducted a field experiment and investigated the effect of sulphur treatments on yield and uptake of Fe, $\mathrm{Mn}$ and $\mathrm{Zn}$ by corn, sorghum and soybeans. The results of their study indicated that elemental sulphur (powder sulphur) decreased the soil PH and increased soil DTPA - extractable Fe, Mn and Zn. Iron and Zn uptake increased while Mn uptake decreased significantly by corn, sorghum and soybeans for almost all the treatments. The main problem of applying sulphur in arable soils is its oxidation after being used. This process can be appropriately done by 
the help of Thiobacillus bacteria in aerobic conditions, but due to the deficient organic matter of soils and thiobacillus bacteria in Iran, it cannot be achieved thoroughly [15].

Sulphur oxidation requires some elements such as microorganisms' activities, suitable temperature, ventilation, moisture, and $\mathrm{PH}$ which are obtained through the application of compost in the soil. Considering the fact that organic matter of calcareous soil is less than others, microorganisms' activities cannot be widely influential in sulphur oxidation; it can be achieved only through utilizing an apposite ventilation and a good supply of soil organic matter. Municipal composts can be a sufficient source of providing soil organic matter to improve its microbial activity. Plant and animal remains in fresh or composted form are also proper sources of soil organic matter [1]. Some scholars have assessed the effects of composts on trees and shrubs and found positive influences of using composts on the growth of abies balsamena [18], populus alba [22] and shrubs of semi-arid Mediterranean area [19] and recovery of decayed soils. Petersen et al [25] examined the effects of municipal composts and sewage sludge in plant nutrition and concluded that there is no limitation in applying them. In spite of some reports which confirm the advantages of using municipal composts in plant nutrition, some researchers have adverted the disadvantages of using composts in the incorporation of tomato [17].

Sarcheshmeh Pour [9] carried out a study and appraised the role of sulphur in nourishing pistachio orchards in Kerman province and found that applying sulphur (alone or with animal manure) in the surface layer of soil cannot be highly effective, but if it is used at a depth of 40 centimetre, it can make significant changes due to biochemical interactions. Pasandideh et al [3] studied the outcomes of using sulphur with thiobacillus inoculum and draw this conclusion that if these two are accompanied with each other, the level of soil PH will be reduced from 7.13 to 6.46 . They stated that thibacillus inoculum is essential to improve sulphur efficiency, but using very high levels cannot be significant in sulphur oxidation. Modaihsh et al [23] examined the effect of elemental sulphur on chemical changes and nutrient availability in calcareous soils and concluded that applied sulphur significantly decreased the $\mathrm{PH}$ and increased the soluble sulphate, iron, copper, manganese, and phosphorus contents.

Goudarzi [13] studied the effects of compost and sulphur on the enhancement of nutrients absorption by wheat and reported that applying sulphur solely can increase the rates of phosphorous, potassium, iron, zinc, and copper in proportion to the control level as follows: $5.5 \%, 11 \%, 39 \%, 5 \%$, and 29\%, while its application with organic manure has increased them respectively $78 \%, 73 \%, 68 \%, 64 \%$, and $54 \%$. Furthermore, several studies demonstrated that if sulphur and thiobacillus bacteria are accompanied with soil phosphate and organic matters, the level of $\mathrm{PH}$ will decrease and required phosphorus for plant nutrition will be supplied [16]. Efficacious composting is subject to some factors such as high quality of compost and its amount, soil type, period of composting, and environmental conditions [3].

\section{Methodology}

The present study investigated the effects of using three types of municipal composts which are powdered compost, sulphur granular compost (15\% sulphur), and sulphur granular compost with thiobacillus inoculum (25 kilograms sulphur for 500 grams thiobacillus inoculums) through the application of complete randomized block design with a $3 \times 5$ factorial experiment in five rates of zero (control), 15, 30, 45, and 60 tons per hectare to incorporate tomato (mobil).

These experiments were simultaneously and separately administered from 2008 to 2010. The obtained results of physical and chemical decomposition of soil and municipal composts in tested regions of Mashhad are shown in tables 1-1 and 1-2. Tested acacia Arabica were permanent and did not change during the process of testing. Corrugation and sprinkler irrigation were used respectively for tomatoes. At the beginning of the period, plants were sampled each three months, then each six months, and at the end, each 12 months to determine significant changes of $\mathrm{SO}_{4}, \mathrm{PH}, \mathrm{EC}_{\mathrm{e}}$ and soil organic carbon. In the middle of the period, the growth of tomato and their level of nutrients, nitrogen, phosphorus, potassium, iron, zinc, manganese, copper, sulphur, and $\mathrm{K}$. Finally, statistical software of MSTAT-C and Duncan's multiple range test were utilized to analyze the achieved data and compare the means.

Table 1. Physical and chemical characteristics of tested planted soils

\begin{tabular}{|c|c|c|c|c|c|c|c|c|c|c|c|}
\hline \multirow[b]{2}{*}{ Plant } & \multirow{2}{*}{$\begin{array}{c}\mathbf{E C e} \\
(\mathbf{d S} / \mathbf{m})\end{array}$} & O.C & T.N.V & \multirow{2}{*}{ pH } & $\mathbf{F e}$ & Mn & $\mathbf{C u}$ & Zn & $\mathbf{P}$ & $\mathbf{K}$ & \multirow{2}{*}{$\begin{array}{l}\text { Soil } \\
\text { type }\end{array}$} \\
\hline & & \multicolumn{2}{|c|}{$(\%)$} & & \multicolumn{6}{|c|}{$\mathbf{m g} / \mathbf{k g})$} & \\
\hline tomato & 1.87 & 0.51 & 19.3 & 8.0 & 2.3 & 14.5 & 1.5 & 0.74 & 7.5 & 221 & loam \\
\hline
\end{tabular}

Table 2. Chemical characteristics of municipal composts of Mashhad

\begin{tabular}{|c|c|c|c|c|c|c|c|c|c|c|c|c|}
\hline \multirow{2}{*}{ Compost } & \multirow{2}{*}{$\begin{array}{c}\mathrm{EC}(\mathbf{1} / \mathbf{5}) \\
(\mathrm{dS} / \mathrm{m})\end{array}$} & \multirow{2}{*}{ pH(1/5) } & O.C & Ash & B & Zn & $\mathbf{C u}$ & Mn & $\mathrm{Fe}$ & $\mathbf{K}$ & $\mathbf{P}$ & $\mathbf{N}$ \\
\hline & & & \multicolumn{2}{|c|}{$(\%)$} & \multicolumn{6}{|c|}{$\mathrm{mg} / \mathrm{kg})($} & & \\
\hline granular & 15.6 & 7.2 & 24 & 60 & 19 & 590 & 540 & 270 & 3890 & 0.61 & 0.46 & 1.65 \\
\hline powdered & 8.5 & 7.3 & 21 & 64 & 19 & 900 & 500 & 450 & 12630 & 0.70 & 0.55 & 1.85 \\
\hline
\end{tabular}


- $\quad$ soil acidity changes

\section{Results and discussion}

By the enhancement of municipal composts, the level of soil PH significantly decreased $(p<0.05)$, but this decrease was reduced by extending the period. While soil PH was about 7.28 for 60 tons per hectare after three months that the test has been started (6\% decrease in proportion to the control level), it was calculated about 7.89 after 36 months (1.6\% decrease in proportion to the control level). It may be the result of neutralizing organic and mineral matters in the compost which is derived from the buffering state of lime existing in the soil. Soil PH decrease in sulphur treatments (sulphur granular compost with or without thiobacillus inoculums) was more than sulphur treatment in powdered compost in a way that they were significantly different from each other.

After 36 months, the least mean of soil PH through the application of sulphur granular compost with thiobacillus inoculums equalled 7.53 (one percent decrease in proportion to powdered compost). From the viewpoint of soil PH decrease, no significant difference was seen between sulphur granular compost with and without thiobacillus.

- Electrical conductivity changes

Increasing the amount of using municipal composts enhanced electrical conductivity of the earth $\left(\mathrm{EC}_{\mathrm{e}}\right)$ $(\mathrm{P}<0.05)$, but soil salinity was reduced by the extension of the period. The obtained findings of the research showed that solute and nutrients concentration can increase the amount of compost salinity. After three months, the highest $\mathrm{EC}_{\mathrm{e}}$ is $9.9 \mathrm{ds} / \mathrm{m}$ when using 60 tons per hectare ( 3.6 times more than the control level, $2.7 \mathrm{ds} / \mathrm{m}$ ). 36 months after starting the research, $\mathrm{EC}_{\mathrm{e}}$ was reduced to $4.2 \mathrm{ds} / \mathrm{m}$; therefore, soil salinity significantly decreased by extending test period. It is alleged that irrigation in the growth period, raining and absorbing nutrients by plants could deplete the level of soil salinity. The capability of $\mathrm{EC}_{\mathrm{e}}$ was about $17 \%$ more than powdered compost when utilizing sulphur treatments (sulphur granular compost with and without thiobacillus), so there was a significant difference between two groups. Among plant species, the highest level of $\mathrm{EC}_{\mathrm{e}}$ was related to apple and acacia trees.

- Soil soluble sulphate changes

Density of soil soluble sulphate significantly increased by increasing the amount of compost usage $(\mathrm{p}<0.05)$ and the highest density was about $38.2 \mathrm{MEq} / \mathrm{l}$ after using 60 tons per hectare. The calculated density was 2.4 times more than the control level (which was15.7 MEq/l). Although the highest amounts of soil soluble sulphate density were calculated for each tested plant, no significant difference was averagely observed between the rates of 15, 30, 45, and 60 tons per hectare. Although the comparison of soil soluble sulphate changes in different times indicated some alterations, it is not significant between sulphur granular compost with and without thiobacillus.

- Soil organic carbon changes

Soil organic carbon significantly increased by enhancing the amount of compost usage $(\mathrm{p}<0.05)$ and the highest soil organic carbon was about $1.6 \%$ after using 60 tons per hectare which was 2.7 times more than the control level (not using compost). The comparison of soil organic carbon changes in different times showed that extending the period of test can decrease organic carbon, however it should be considered that the amount of decrease was more noticeable when applying more composts.

This outcome can be the consequence of the fact that organic carbon retention in soil is too short due to dry climate, high temperature and tillage operations such as ploughing. Owing to the fact that carbon is instantaneously decomposed and ascends into the atmosphere, no significant difference was recognized between soil organic carbon in control treatment (not using compost) and after using 60 tons of municipal composts per hectare.

The findings of the research demonstrated that applying sulphur compost increased soil organic carbon about $13 \%$. This result probably emerged due to the fact that the amount of organic carbon of granular compost was more than powdered compost. Although soil organic carbon of powdered compost was augmented from $0.45 \%$ to $0.95 \%$ after using 60 tons per hectare, no significant different could be considered between two types of sulphur composts. Based on the results, the longest retention of organic manures (compost) was about two years in soil.

\section{- Performance indexes}

a) Tomato

The achieved results of the first year (2008) showed that using 45 tons composts per hectare is more effective than other amounts to improve tomato performance. Moreover, the type of used compost was significantly influential in tomato performance and sulphur granular compost was more beneficial in comparison 
to two other types $(\mathrm{p}<0.05)$. In the second year (2009), 60 tons were averagely the most effective, while the type of used compost was not significantly controlling. In the third year (2010) 60 tons were again the most influential, but the significant type was sulphur granular compost with thiobacillus.

The average of three years of applying three types of municipal composts proved that by increasing the amount of each type of composts, tomato performance is significantly augmented in a way that after using 60 tons of sulphur granular compost, sulphur granular compost with thiobacillus, and powdered compost, tomato performance was respectively increased about $68 \%, 58 \%$ and $44 \%$ in proportion to the control treatment (not using compost). Mention must be made though that on the basis of correlation coefficient between tomato performance ( $\mathrm{y}$, tons per hectare) and used granular compost ( $\mathrm{x}$, tons per hectare), the highest tomato performance can be achieved by applying 84.6 tons of granular composts per hectare.

Besides the aforementioned elements which could change the performance and were observed through the period of three years, some other factors exist such as extending the test period that can decrease the performance. It may be the consequence of repeated incorporation of tomato in the same place (situ cultivation), annual impacts of climate, and the depletion of beneficial effects of compost on soil and plant after some time. Assessing the density of nutrients in tomato leaves demonstrated that increasing the amount of compost can only add to the density of leaves' zinc, iron and manganese in the way that using 60 tons of composts per hectare could increase zinc density about $27 \%$ of tomato leaves in proportion to the control level (not using compost).

The obtained results of conducting the research during a period of three years indicated that there is no significant relationship between different types of used composts from the viewpoint of their effects on the elements' density in tomato leaves.

\section{Conclusion}

The achieved results showed that after applying composts and extending the period of experiment, soil PH increased after a gradual decrease in the first year. Mohammad and Mazahreh [24] stated that soil PH decrease is caused due to the effects of using organic manures (sewage) and releasing hydrogen ions resulting from nitrification process.

However, Khoshgoftar Manesh and Kalbasi [5] related this issue to the existence of organic and mineral acids in organic manures. The depletion of soil $\mathrm{PH}$ was not permanent during the process of conducting the experiments due to some factors which can be explained in the following manner: the existence of lime, buffering characteristics of soil, neutralizing the organic and mineral acids existing in the composts [26]. These results were opposite about the amount of electrical conductivity and density of soil soluble sulphate and soil organic carbon in a way that after a noticeable increase in the first year, it decrease gradually in the following years. Although the effects of compost on tested plants performance were reduced, its impacts existed until the second year. Considering the findings, using municipal composts was beneficial in the improvement of tomato. Rajaei and Karimian [7] found that using municipal composts can increase tomato development in all usage levels (zero to 40 grams per kilogram of soil).

\section{REFERENCES}

[1] Asgharzadeh, A., Malakouti, M.J., Bahrami, H., and Ebrahimi, S. (2004). Organic matter and its role in amending characteristics of the country's soils, Iran's soils, in Banayi et al. (eds.), Soil and Water Research Institute, Mashhad, Iran, p. 213. [In Persian.]

[2] Besharati, H., Nourgholi Pour, F., and Khavazi, K. (2006). The assessment of sulphur efficiency and Thiobacillus inocula in the absorption of nutrients and corn performance in calcareous soils. Water and Soil Science, 20, 249-261. [In Persian.]

[3] Bradford, G.R., Page, A.L., Lund, L.J., and Olmstead, W. (1975). Trace element concentrations of sewage treatment plant effluents and sludges; their interactions with soils and uptake by plants. J. Environ. Qual. 4, 123-127. http://dx.doi.org/10.2134/jeq1975. $00472425000400010029 x$

[4] Bramryd, T. (2001). Effects of liquid and dewatered sewage sludge applied to a scots pine stand (Pinus sylvestris L.) in Central Sweden. Forest Ecol. Manag. 147, 197-216. http://dx.doi.org/10.1016/S0378-1127(00)00476-X

[5] Caravaca, F., Figueroa, D., Alguacil, M.M., and Roldán, A. (2003). Application of composted urban residue enhanced the performance of afforested shrub species in a degraded semiarid land. Bioresour. Technol. 90, 65-70. http://dx.doi.org/10.1016/S0960-8524(03)00087-7

[6] Cifuentes, F.R. and Lindermann, W.C. (1993). Organic matter stimulation of elemental sulfur oxidation in calcareous soil. Soil Sci. Soc. Am. J. 57, 727-731.

[7] Goudarzi, K. (2005). The effects of sulphur and compost on the enhancement of nutrients' absorption by wheat in calcareous soils. Ninth conference of Iran's soil science, Tehran, 1, 122-137. [In Persian.]

[8] Hassan Oghli, A.R., Liaghat, A., and Mirabzadeh, M. (2002). Soil organic matters' changes resulting from irrigation by sanitary sewage and its self-purification. Journal of Water and Sewage 42, 2-11. [In Persian.]

[9] Kalbasi, M., Filsoof, F., and Rezai-Nejad, Y. (1988). Effect of sulfur treatment on yield and uptake of Fe, Zn, and Mn by corn, sorghum, and soybeans. J. Plant Nutr. 11, 1353-1360. http://dx.doi.org/10.1080/01904168809363892

[10] Keshavarz, P. and Malakouti, M.J. (2003). The role of zinc in the decrease of salinity. Technical journal of the Soil and Water Research Institute, issue 298, 27-39. [In Persian.]

[11] Keshavarz, P. (2006). The effects of organic matters' increase on arable soils and methods of developing its consumption in Khorasan Razavi province. Final report, Jahad Agriculture Organization of Khorasan Razavi, 221. [In Persian.]

[12] Khoshgoftar Manesh, A.H. and Kalbasi, M. (1999). The effects of leachate on rice and wheat improvement and performance. Sixth conference of Iran's soil science, Ferdowsi University of Mashhad. [In Persian.] 
[13] Khoshgoftar Manesh, A.H. and Kalbasi, M. (2002). The effects of leachate on soil characteristics and wheat performance. Science and Technology of Agriculture and Natural Resources 3, 141-148. [In Persian.]

[14] Malakouti, M.J. (1996). Increasing the stability of agriculture and performance by optimizing manure consumption in Iran, TAT Education and Human Resources Facilities, Department of Agriculture, p. 279, Karaj, Iran. [In Persian.]

[15] Malakouti, M. J. and Keshavarz, P. (2005). Iran's soils productivity. Ministry of Jahad Agriculture, p. 503. [In Persian.]

[16] McIntosh, M.S., Foss, J.E., Wolf, D.C., Brandt, K.R., and Darmody, R. (1984). Effect of composted municipal sewage sludge on growth and elemental composition on white pine and hybrid poplar. J. Environ. Qual., 13, 60-62. http://dx.doi.org/10.2134/jeq1984.00472425001300010010x

[17] Modaihsh, S., Al-Mustafa, W.A., and Metwally, A.E. (1989). Effect of element sulfur on chemical changes and nutrient availability in calcareous soils. Plant Soil 116, 95-101. http://dx.doi.org/10.1007/BF02327261

[18] Mohammad, M.J. and Mazahreh, N. (2003). Changes in soil fertility parameters in response to irrigation of forage crops with secondary treated wastewater. Commun. Soil Sci. Plan. 34, 1281-1294. http://dx.doi.org/10.1081/CSS-120020444.

[19] Mohammadi Nia, G. (1995). Chemical composition of leachate and compost and their effects on soils and plants. M.A. thesis in Agrology, Department of Agricultural Engineering, Isfahan University of Technology. [In Persian.]

[20] Pasandideh, M., Malakouti, M.J., and Keshavarz, P. (2003). The effects of sulphur and Thiobacillus inocula on sulphur oxidation, $\mathrm{pH}$ content of manure pit and phosphorus acquirement from golden bio-phosphate fertilizer. The first national conference of sulphur production and consumption in the country, Mashhad, 82-89. [In Persian.]

[21] Petersen, S.O., Henriksen, K., Mortensen, G.K., Krogh, P.H., Brandt, K.K., Sørensen, J., Madsen, T., Petersen, J., and Grøn, C. (2003). Recycling of sewage sludge and household compost to arable land: fate and effects of organic contaminants, and impact on soil fertility. Soil Till. Res. 72, 139-152. http://dx.doi.org/10.1016/S0167-1987(03)00084-9

[22] Rajaei, M. and Karimian, N. (1999). Mutual effects of compost and nitrogen on tomato improvement, capability of nitrogen usage, and some specific characteristics of soil in greenhouse conditions. Sixth conference of Iran's soil science, Ferdowsi University of Mashhad, 152-163. [In Persian.]

[23] Razi Kord Mahaleh, L. and Asgharzadesh, A. (2007). The effect of microorganisms' inoculation on sulphur oxidation and making multipurpose composts during the process of composting bagasse. Zeytoon 177, 14-21. [In Persian.]

[24] Sahebjam, A.A. (2002). Studies of agrology and stratification of arable lands applied to agricultural researches of Torogh Town in Khorasan Razavi province, final report, issue 1146, Soil and Water Research Institute, 71-94. [In Persian.]

[25] Sarcheshmeh Pour, M. (2003). The role of sulphur in nourishing pistachio orchards in Kerman province and the necessity of amending the consumption approaches. The first national conference of sulphur production and consumption in the country, Mashhad, 36-44. [In Persian.]

[26] Schipper, L.A., Williamson, J.C., Kettles, H.A., and Speir, T.W. (1996). Impact of land-applied tertiary-treated effluent on soil properties. J. Environ. Qual. 25, 1073-1077. http://dx.doi.org/10.2134/jeq1996.00472425002500050020x

[27] Vazquez-Montiel, O., Horan, N.J., and Mara, D.D. (1996). Management of domestic wastewater for reuse in irrigation. Water Sci. Technol. 33, 355-362. http://dx.doi.org/10.10.1016/0273-1223 (96)00438-6. 